\title{
Electronic and atomic structure of the AlnHn+2 clusters
}

Martinez, Jose Ignacio; Alonso, J.A.

Published in:

Journal of Chemical Physics

Link to article, DOI:

$10.1063 / 1.2960627$

Publication date:

2008

Document Version

Publisher's PDF, also known as Version of record

Link back to DTU Orbit

Citation (APA):

Martinez, J. I., \& Alonso, J. A. (2008). Electronic and atomic structure of the AlnHn+2 clusters. Journal of Chemical Physics, 129(7), 074306. https://doi.org/10.1063/1.2960627

\section{General rights}

Copyright and moral rights for the publications made accessible in the public portal are retained by the authors and/or other copyright owners and it is a condition of accessing publications that users recognise and abide by the legal requirements associated with these rights.

- Users may download and print one copy of any publication from the public portal for the purpose of private study or research.

- You may not further distribute the material or use it for any profit-making activity or commercial gain

- You may freely distribute the URL identifying the publication in the public portal

If you believe that this document breaches copyright please contact us providing details, and we will remove access to the work immediately and investigate your claim 


\title{
Electronic and atomic structure of the $\mathrm{Al}_{n} \mathrm{H}_{n+2}$ clusters
}

\author{
J. I. Martínez ${ }^{1,2, a)}$ and J. A. Alonso, \\ ${ }^{1}$ Departamento de Física Teórica, Atómica y Óptica, Universidad de Valladolid, E-47011 Valladolid, Spain \\ ${ }^{2}$ Center for Atomic-Scale Materials Design, Department of Physics, NanoDTU, Technical University \\ of Denmark, DK-2800 Kgs. Lyngby, Denmark \\ ${ }^{3}$ Donostia International Physics Center (DIPC), E-20018 San Sebastian, Spain
}

(Received 7 April 2008; accepted 26 June 2008; published online 18 August 2008)

\begin{abstract}
The electronic and atomic structure of the family of hydrogenated $\mathrm{Al}$ clusters $\mathrm{Al}_{n} \mathrm{H}_{n+2}$ with $n$ $=4-11$ has been studied using the density functional theory with the generalized gradient approximation (GGA) for exchange and correlation. All these clusters have substantial gaps between the highest occupied and the lowest unoccupied molecular orbitals (HOMO-LUMO) and, consequently, they are chemically very stable. The largest gap of $2.81 \mathrm{eV}$ occurs for $\mathrm{Al}_{6} \mathrm{H}_{8}$. Five clusters of the family, $\mathrm{Al}_{4} \mathrm{H}_{6}, \mathrm{Al}_{5} \mathrm{H}_{7}, \mathrm{Al}_{6} \mathrm{H}_{8}, \mathrm{Al}_{7} \mathrm{H}_{9}$, and $\mathrm{Al}_{10} \mathrm{H}_{12}$, fulfill the Wade-Mingos rule. That is, in $\mathrm{Al}_{n} \mathrm{H}_{n+2}$, the $\mathrm{Al}$ matrix forms a polyhedron of $n$ vertices and $n \mathrm{H}$ atoms form strong $\mathrm{H}-\mathrm{Al}$ terminal bonds; one pair of electrons is involved in each of those bonds. The remaining $n+1$ electron pairs form a delocalized cloud over the surface of the $\mathrm{Al}$ cage. The clusters fulfilling the Wade-Mingos rule have wider HOMO-LUMO gaps and are chemically more stable. The trends in the gap have some reflections in the form of the photoabsorption spectra, calculated in the framework of time-dependent density functional theory using the GGA single-particle energies and orbitals and a local density approximation exchange-correlation kernel. () 2008 American Institute of Physics. [DOI: 10.1063/1.2960627]
\end{abstract}

\section{INTRODUCTION}

Small atomic clusters represent a form of matter with unexpected properties and with a potential for a great number of applications in nanotechnology. One of the most interesting characteristics of clusters is the variation of the stability as a function of the cluster size, which shows up in the abundance mass spectrum measured in cluster beams ${ }^{1,2}$ as pronounced peaks, usually called magic numbers. The reasons underlying the enhanced stability of the magic clusters are well known in many simple cases ${ }^{2}$ but not in other more complex ones, which still require an explanation. Aluminum and boron are elements in the same group of the periodic table. While boron forms many hydrides, known as the boranes, it was thought that aluminum forms only a few hydrides. ${ }^{3-8}$ Nevertheless, by reacting $\mathrm{Al}_{n}^{-}$cluster anions $(n=3-20)$ with a high concentration of hydrogen, about 200 previously unobserved aluminum hydride anions have recently been detected by Li et al. ${ }^{9}$ The mass spectrum showed the special and unexpected stability of $\mathrm{Al}_{4} \mathrm{H}_{6}$, and this was explained on the basis of the Wade-Mingos (WM) rules for electron counting, suggesting that $\mathrm{Al}_{4} \mathrm{H}_{6}$ may be a borane analog. These experimental results have motivated us to look at other aluminum hydrides of the $\mathrm{Al}_{n} \mathrm{H}_{n+2}$ family.

The WM rules were originally established to relate the geometries of $\mathrm{B}_{n} \mathrm{H}_{n}^{-2}$ boranes, which contain $2 n+1$ valence electron pairs, to their electronic structures. The best known form of the WM rules ${ }^{10-16}$ states that $n$ of those pairs are required to form the $\mathrm{B}-\mathrm{H}$ terminal bonds, leaving $n+1$ pairs for cage bonding. The WM $n+1$ rule states that a borane

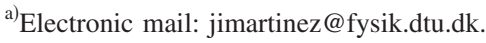

with $n+1$ electron pairs for the boron skeletal bonding will have a metallic matrix based on an $n$-vertex polyhedron. This is the case of $\mathrm{B}_{6} \mathrm{H}_{6}^{-2}$, where the six $\mathrm{B}$ atoms form an octahedral structure. In addition to the boranes and the $\mathrm{Al}_{4} \mathrm{H}_{6}$ alane, WM rules have been successful in relating electronic structure to geometric structure in other classes of clusters.

In a recent study Kiran et al. ${ }^{17}$ have studied other clusters formed by aluminum and hydrogen with stoichiometries rich in aluminum. They proposed an electron counting rule enabling to predict the size, composition, and structure of magic clusters: $\mathrm{Al}_{6} \mathrm{H}_{2}, \mathrm{Al}_{7} \mathrm{H}_{1}, \mathrm{Al}_{7} \mathrm{H}_{3}, \mathrm{Al}_{8} \mathrm{H}_{4}, \mathrm{Al}_{13} \mathrm{H}_{1}$, and $\mathrm{Al}_{14} \mathrm{H}_{2}$. The work on alanes ${ }^{9,17}$ is usually motivated by the interest in finding materials with a good capacity to store hydrogen and our study, apart from testing the applicability of the WM rules, also shares that motivation.

In this paper we present a theoretical study of the atomic and the electronic structures of clusters of the family $\mathrm{Al}_{n} \mathrm{H}_{n+2}$ with $n=4-11$, using the density functional theory (DFT). To our knowledge, only one cluster of this family, $\mathrm{Al}_{4} \mathrm{H}_{6}$, has been studied before. ${ }^{9}$ One of the questions that we analyze is the extent to which those clusters fulfill the WM rule. In addition we make predictions of the photoabsorption spectra of these clusters, and for that purpose we use the timedependent DFT (TDDFT) (Refs. 18 and 19) to calculate the electronic excitations.

\section{STRUCTURE AND ELECTRONIC PROPERTIES}

In the calculation of the atomic and the electronic structures of pure aluminum clusters and their hydrides we have used the ABINIT code, ${ }^{20}$ in which the Kohn-Sham (KS) equations of DFT are solved using a periodic supercell geometry. The electronic wave functions are expanded in a basis of 
TABLE I. Pseudopotential parameters for $\mathrm{H}$ and Al. $r_{l}(l=0,1)$ are the cutoff radii (in atomic units), $l_{\max }$ is the maximum angular momentum, and $l_{\mathrm{loc}}$ stands for the angular momentum of the local part of the pseudopotential. $Z_{\text {atom }}$ is the atomic number and $Z_{\text {ion }}$ is the charge.

\begin{tabular}{lccccccc}
\hline \hline & $\mathrm{Z}_{\text {atom }}$ & $\mathrm{Z}_{\text {ion }}$ & Configuration & $r_{l=0}$ & $r_{l=1}$ & $1_{\max }$ & $1_{\text {loc }}$ \\
\hline $\mathrm{H}$ & 1 & 1 & $1 s^{1}$ & 1.25 & $\ldots$ & 0 & 0 \\
$\mathrm{Al}$ & 13 & 3 & $3 s^{2} 3 p^{1}$ & 2.28 & 2.28 & 1 & 1 \\
\hline \hline
\end{tabular}

plane waves. The interaction between the valence electrons and the ions has been modeled by replacing the ionic cores by Troullier-Martins ${ }^{21}$ pseudopotentials generated with the FHI98PP package. $^{22}$ The parameters characterizing the pseudopotentials are given in Table I.

We have used a cubic supercell of size $30 \times 30$ $\times 30$ a.u. ${ }^{3}$, an energy cutoff of 50 Ry for the basis of plane waves and a single $k$ point in reciprocal space. The supercell size and the cutoff have been adjusted to achieve sufficient accuracy in the total energy. For exchange and correlation (XC) effects we have used the Perdew-Burke-Erzenhof (PBE) functional ${ }^{23}$ within the generalized gradient approximation (GGA). We have also performed some tests using other more complex XC functionals: The van LeeuwenBaerends functional, ${ }^{24}$ which improves the asymptotic behavior of the XC potential, and the hybrid PBE0 functional, ${ }^{25}$ which mixes the PBE functional with a fraction (0.25) of the exact exchange. The results obtained show no significant differences in comparison to the results of the PBE functional. Actually, the PBE0 functional has been used for testing the most stable $\mathrm{Al}_{n} \mathrm{H}_{n+2}$ structures and their main isomers, obtaining the same ground-state structures and the same isomer energy ordering as with the PBE functional. Consequently, the PBE functional has been employed through the paper in order to reduce the computational effort.

\section{A. Structures of pure Al clusters and their hydrides}

As a first step we have studied pure $\mathrm{Al}_{n}$ clusters. By starting with the structures reported by Rao and Jena, ${ }^{26}$ we have reoptimized the structures and the results are shown in Fig. 1 for $n=4-11$. The optimized structures are in good agreement with the starting geometries, except for the $\mathrm{Al}_{4}$ and $\mathrm{Al}_{5}$. According to the present calculations, those two clusters have nonplanar $\mathrm{C}_{2 v}$ and $\mathrm{D}_{3 h}$ symmetries, respectively, instead of the planar structures previously obtained. $\mathrm{Al}_{6}$ is a distorted octahedron, and $\mathrm{Al}_{7}$ and $\mathrm{Al}_{8}$ have the octahedral structure with one and two faces capped by $\mathrm{Al}$ atoms, respectively. For $n=7$ and 8 we also include in the figure one and two metastable isomers, respectively, lying close in energy above the ground state. Those low lying isomers have also been taken as additional starting geometries for the investigation of the hydrides. $\mathrm{Al}_{9}$ can be seen as formed by two fused trigonal bipyramids, sharing one face, and then adding two $\mathrm{Al}$ atoms in bridge positions, one to each bipyramid. $\mathrm{Al}_{10}$ is a cube, a little distorted, and with two opposite faces capped by $\mathrm{Al}$ atoms. Finally, $\mathrm{Al}_{11}$ is the last cluster without internal atoms. Starting from $n=12$, Rao and Jena ${ }^{26}$ predicted structures showing at least one endohedral atom, and for this reason we have not studied clusters with more than eleven $\mathrm{Al}$ atoms.
Previous work on hydrogenated $\mathrm{Al}$ clusters indicates that the $\mathrm{H}$ atoms stay on the surface of the $\mathrm{Al}$ matrix, ${ }^{17,27}$ and that hydrogenation affect the structure of the matrix a little. Then, for the construction of the starting geometries, we have taken the pure $\mathrm{Al}$ clusters of Fig. 1 as cores for the hydrogenated clusters. The optimal structures of the $\mathrm{Al}_{n} \mathrm{H}_{n+2}$ clusters have been obtained by relaxing several dozens of initial geometries with the $\mathrm{H}$ atoms added to the surface of $\mathrm{Al}_{n}$ at different positions: On top of $\mathrm{Al}$ atoms (top sites), on $\mathrm{Al}-\mathrm{Al}$ bonds (bridge sites), and on the faces (face sites). During the structural relaxations all atoms are free to move, and a steepestdescent algorithm with a convergence criterion of $10^{-2} \mathrm{eV} / \AA$ for the force on every atom has been used. It is noticeable that the ground state is obtained from a large number of starting geometries, giving credibility to the optimized structure. In addition, we have performed a number of tests for starting geometries with $\mathrm{H}$ atoms in the inner region of the $\mathrm{Al}$ clusters, and these calculations revealed that structures with endohedral $\mathrm{H}$ impurities are not favored, at least for the sizes and $\mathrm{H}$ concentrations studied in this work; those initial endohedral structures always evolve toward structures with all the $\mathrm{H}$ atoms in exohedral positions. The most stable structures obtained for the $\mathrm{Al}_{n} \mathrm{H}_{n+2}$ alanes with $n=4-11$ are shown in Fig. 2.

$\mathrm{Al}_{4} \mathrm{H}_{6}$ keeps the tetrahedral structure of the $\mathrm{Al}_{4}$ matrix structure practically unaltered. To gain some insight into the process of hydrogenation, additional calculations for $\mathrm{Al}_{4} \mathrm{H}_{m}$

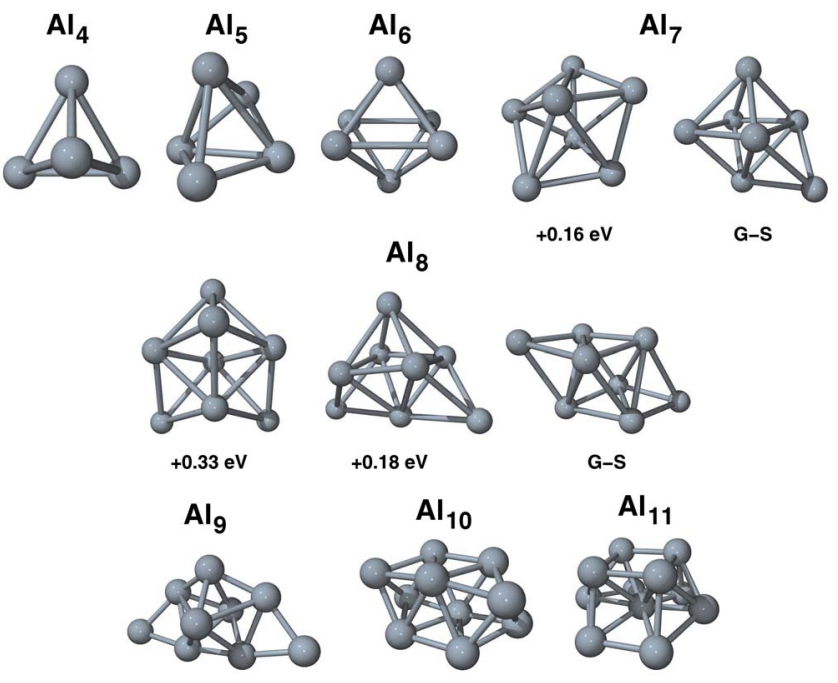

FIG. 1. (Color online) Optimized structures of $\mathrm{Al}_{n}$ clusters with $n=4-11$. The geometries belong to the $\mathrm{C}_{2 v}$ symmetry group for $n=4$ (distorted tetrahedron), $\mathrm{D}_{3 h}$ for $n=5$ (triangular bipyramid), and $\mathrm{O}_{h}$ for $n=6$ (square bipyramid). For $\mathrm{Al}_{7}$ and $\mathrm{Al}_{8}$ the two and three most stable isomers are shown, respectively, including the energy difference with respect to the most stable structure (ground state). 

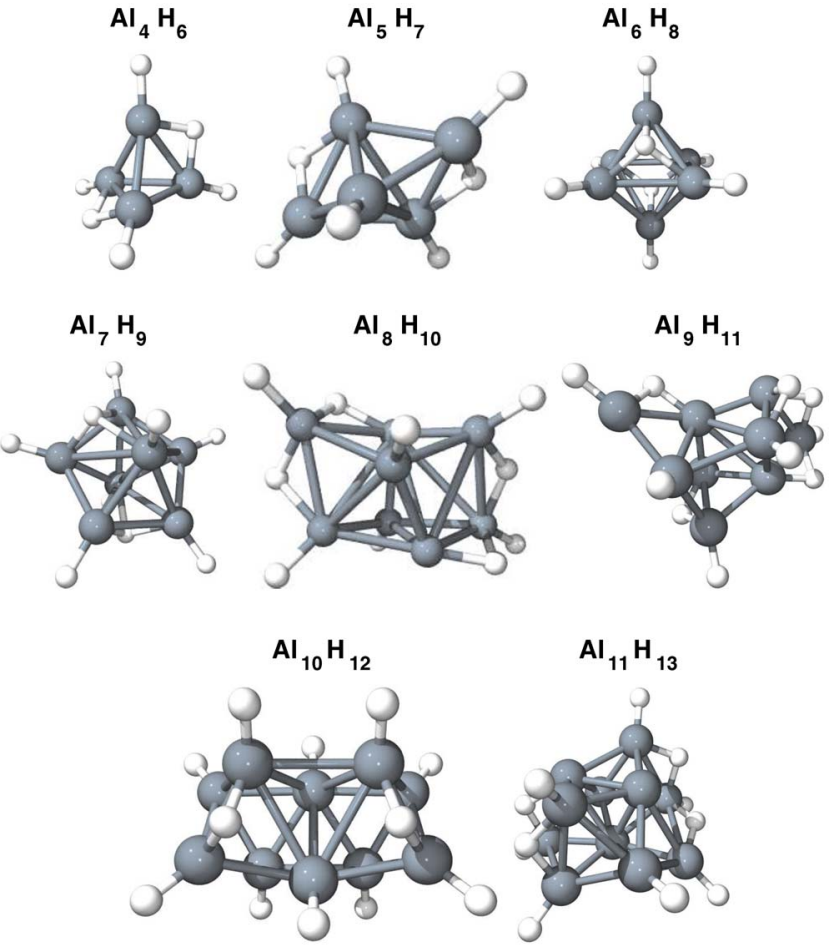

FIG. 2. (Color online) Most stable structures of neutral $\mathrm{Al}_{n} \mathrm{H}_{n+2}$ clusters up to $n=11$. The dark and light spheres represent the $\mathrm{Al}$ and the $\mathrm{H}$ atoms, respectively.

clusters with $m=4,5$, and 7 have been performed. In $\mathrm{Al}_{4} \mathrm{H}_{4}$, the four $\mathrm{H}$ atoms are located on top positions, that is, each $\mathrm{H}$ atom forms a covalent bond with an $\mathrm{Al}$ atom. In $\mathrm{Al}_{4} \mathrm{H}_{5}$, $\mathrm{Al}_{4} \mathrm{H}_{6}$, and $\mathrm{Al}_{4} \mathrm{H}_{7}$, four $\mathrm{H}$ atoms are on top positions and the additional $\mathrm{H}$ atoms occupy bridge positions. $\mathrm{Al}_{4} \mathrm{H}_{6}$ has been found very abundant in the mass spectrum of $\mathrm{Al}_{4} \mathrm{H}_{m}$ by $\mathrm{Li}$ et $a l^{9}$ and its stability was attributed to the fulfillment of the WM rules for electron counting.

The structure of the $\mathrm{Al}$ matrix is also preserved practically unaltered in $\mathrm{Al}_{5} \mathrm{H}_{7}$ and $\mathrm{Al}_{6} \mathrm{H}_{8}$. In $\mathrm{Al}_{5} \mathrm{H}_{7}$, five $\mathrm{H}$ atoms are on top positions and two $\mathrm{H}$ atoms in bridge positions. In $\mathrm{Al}_{6} \mathrm{H}_{8}$, six $\mathrm{H}$ atoms occupy top positions on the octahedral matrix and the other two occupy face positions. The groundstate structure of $\mathrm{Al}_{7} \mathrm{H}_{9}$ is found by starting with the two $\mathrm{Al}_{7}$ isomers of Fig. 1. The structure of the $\mathrm{Al}$ core in $\mathrm{Al}_{7} \mathrm{H}_{9}$ does not correspond to that of the ground state of $\mathrm{Al}_{7}$, but to that of the other isomer (a pentagonal bipyramid). This breaks the trend observed for the smaller clusters. The hydrogen decoration in $\mathrm{Al}_{7} \mathrm{H}_{9}$ conforms to the usual picture: Seven $\mathrm{H}$ atoms sit on top positions and two $\mathrm{H}$ atoms on face positions. The most stable structure of $\mathrm{Al}_{8} \mathrm{H}_{10}$ is only obtained from the most stable $\mathrm{Al}_{8}$ isomer of Fig. 1, just as for $n=4,5$, and 6 . For all of them, the structure of the Al core of the hydrogenated cluster shows only slight modifications with respect to the structure of the pure $\mathrm{Al}_{n}$ cluster. Six hydrogen atoms of $\mathrm{Al}_{8} \mathrm{H}_{10}$ occupy top positions and the other four $\mathrm{H}$ atoms are in bridge positions. The $\mathrm{Al}$ core of $\mathrm{Al}_{9} \mathrm{H}_{11}$ arises as a small distortion of pure $\mathrm{Al}_{9}$. Six $\mathrm{H}$ atoms are attached to this structure in top positions, and the other five $\mathrm{H}$ atoms in bridge sites. Finally, the distortions of the $\mathrm{Al}$ core of $\mathrm{Al}_{10} \mathrm{H}_{12}$ and $\mathrm{Al}_{11} \mathrm{H}_{13}$ with respect to clean $\mathrm{Al}_{10}$ and $\mathrm{Al}_{11}$, respectively, are strong. In $\mathrm{Al}_{10} \mathrm{H}_{12}$, with the form of a distorted pentagonal antiprysm, ten $\mathrm{H}$ atoms are attached in top positions to the vertices of the antiprysm and two in bridge positions. In $\mathrm{Al}_{11} \mathrm{H}_{13}$, the numbers of top and bridge $\mathrm{H}$ atoms are 8 and 5 , respectively. In all these clusters, the $\mathrm{H}-\mathrm{Al}$ distances for $\mathrm{H}$ atoms in top positions are close to $1.58 \AA$ (this distance is typical of the $\mathrm{AlH}$ molecule ${ }^{28}$ ), while the $\mathrm{H}-\mathrm{Al}$ distances for $\mathrm{H}$ atoms on bridge and face sites show variations and the values depend on each particular structure. The only cluster of this series that can be compared to previous work is $\mathrm{Al}_{4} \mathrm{H}_{6}$. For this cluster $\mathrm{Li}$ et al. ${ }^{9}$ obtained a structure of a distorted tetrahedron with four terminal $\mathrm{H}$ atoms (four $\mathrm{Al}-\mathrm{H}$ bonds) and two bridging $\mathrm{H}$ atoms. Our structure for this cluster is the same. Although a more extensive search could be done, we think that the structures of the hydrogenated clusters given in Fig. 2 represent the lowest energy structures or are very close to them. First of all, we have seen that the structural relaxation of the hydrogenated clusters allows for strong changes in the starting structure, and that those changes also affect the Al core. On the other hand, when we have relaxed the geometries of the hydrogenated clusters by starting with several isomers of the corresponding $\mathrm{Al}_{n}$ core, the lowest energy structure of the hydrogenated cluster has always been found in the relaxations starting from the ground-state $\mathrm{Al}_{n}$ core (sometimes, as for $\mathrm{Al}_{7} \mathrm{H}_{9}$, the lowest energy structure is also obtained starting from other isomers).

To be consistent with the structural formulation of the WM rule (or $n+1$ rule), a cluster $\mathrm{Al}_{n} \mathrm{H}_{n+2}$, with $2 n+1$ electron pairs (each $\mathrm{Al}$ atom contributes three electrons and each $\mathrm{H}$ atom one), should employ $n$ electron pairs for $\mathrm{Al}-\mathrm{H}$ terminal bonds and the remaining $n+1$ pairs for cage bonding, and the structure should be based on an $\mathrm{Al}$ polyhedron with $n$ vertices. Clusters $\mathrm{Al}_{4} \mathrm{H}_{6}, \mathrm{Al}_{5} \mathrm{H}_{7}, \mathrm{Al}_{6} \mathrm{H}_{8}, \mathrm{Al}_{7} \mathrm{H}_{9}$, and $\mathrm{Al}_{10} \mathrm{H}_{12}$ fit well into this picture. All those clusters show $\mathrm{Al}_{n}$ skeletal cages with $n$ vertices and have $n$ hydrogen atoms on top positions (see Fig. 2). An analysis of the electron density in Sec. II B below shows that $n$ electron pairs contribute to $\mathrm{Al}-\mathrm{H}$ radial bonds, and that the other $n+1$ electron pairs form a rather delocalized cloud responsible for cage bonding. On the other hand, $\mathrm{Al}_{8} \mathrm{H}_{10}, \mathrm{Al}_{9} \mathrm{H}_{11}$, and $\mathrm{Al}_{11} \mathrm{H}_{13}$ do not conform to that rule. For instance, in $\mathrm{Al}_{8} \mathrm{H}_{10}$, four $\mathrm{H}$ atoms are located in bridge positions, and therefore there are only six $\mathrm{H}$ atoms forming terminal $\mathrm{Al}-\mathrm{H}$ bonds. In a similar way the number of $\mathrm{H}$ atoms forming terminal bonds with $\mathrm{H}$ in $\mathrm{Al}_{9} \mathrm{H}_{11}$ and $\mathrm{Al}_{11} \mathrm{H}_{13}$ is smaller than 9 and 11, respectively. According to Rao and Jena, ${ }^{26} \mathrm{Al}_{12}$ and larger pure $\mathrm{Al}$ clusters have an $\mathrm{Al}$ atom in an endohedral location, so we have not considered clusters with 12 or more $\mathrm{Al}$ atoms in our study. Returning to the $\mathrm{Al}_{n} \mathrm{H}_{n+2}$ clusters with $n$ hydrogen atoms in top sites, the two additional $\mathrm{H}$ atoms of $\mathrm{Al}_{4} \mathrm{H}_{6}$ and $\mathrm{Al}_{5} \mathrm{H}_{7}$ are located in bridge sites, and occupying face sites in $\mathrm{Al}_{6} \mathrm{H}_{8}, \mathrm{Al}_{7} \mathrm{H}_{9}$, and $\mathrm{Al}_{10} \mathrm{H}_{12}$. That is, a change from $\mathrm{H}$ atoms on bridge sites to face sites occurs in the alanes between $\mathrm{Al}_{5} \mathrm{H}_{7}$ and $\mathrm{Al}_{6} \mathrm{H}_{8}$.

The highest occupied molecular orbital-lowest unoccupied molecular orbital (LUMO) (H-L) gaps of the $\mathrm{Al}_{n} \mathrm{H}_{n+2}$ clusters, calculated as a difference between the $\mathrm{KS}$ energies of the corresponding one electron orbitals, are reported in Fig. 3. The gaps are large, exhibiting values ranging between 1.35 and $2.8 \mathrm{eV}$, giving idea of the stability of those clusters. 


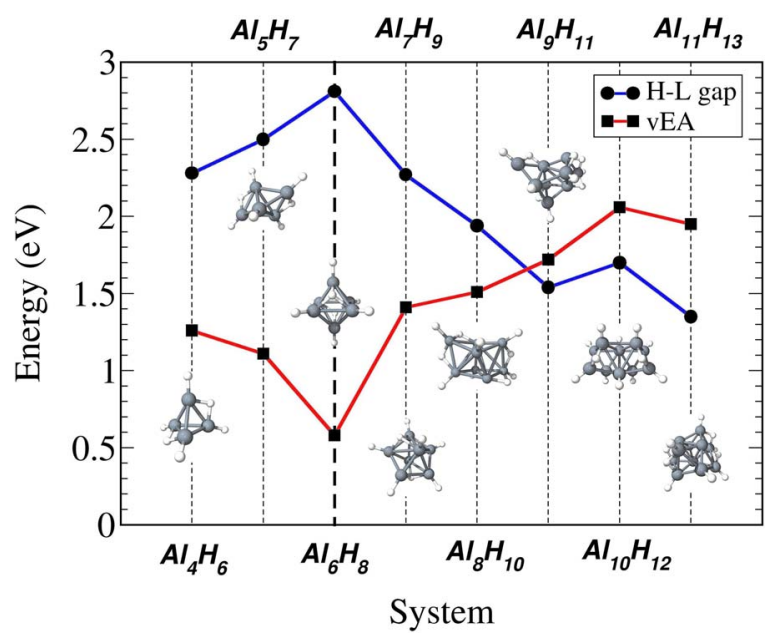

FIG. 3. (Color online) H-L gaps and EA of $\mathrm{Al}_{n} \mathrm{H}_{n+2}$ clusters with $n=4-11$.

The largest $\mathrm{H}-\mathrm{L}$ gap occurs for $\mathrm{Al}_{6} \mathrm{H}_{8}$. A local maximum for $\mathrm{Al}_{10} \mathrm{H}_{12}$ is also noticeable, which breaks the trend of decreasing gap on the right side of $\mathrm{Al}_{6} \mathrm{H}_{8}$. The calculated gap of $\mathrm{Al}_{4} \mathrm{H}_{6}$ is $2.2 \mathrm{eV}$, in good agreement with the experimental value of $1.9 \mathrm{eV} .{ }^{9}$ Figure 3 also includes the electronic affinities (EAs). These have been calculated as a difference of the total energies of the anionic and the neutral clusters. To avoid problems related to the long range electrostatic interaction between charged supercells which arise in a periodic supercell calculation for the anionic species, calculations for the neutral and anionic clusters have been performed with the real-space DFT code OCTOPUS. ${ }^{29}$ The main numerical parameters that need to be specified in these calculations are the spacing of the spatial mesh, $0.18 \AA$, and the wave function domain, a sphere of radius $9.5 \AA$. To be consistent, the geometries of the neutral clusters were reoptimized with the OCTOPUS code. The structures of the negatively charged clusters have also been fully relaxed, taking as starting geometries those of the neutrals. In all cases the structural relaxation process immediately finishes using the same convergence criterion for atomic forces $\left(10^{-2} \mathrm{eV} / \AA\right) \mathrm{em}$ ployed above for the neutral clusters. This behavior can be understood from the high stability of these clusters, which can accommodate an extra electron without experiencing any variation of the geometrical structure. This means that the vertical and adiabatic electron affinities are nearly the same. Confirmation of this effect is observed in the experiments. The measured adiabatic affinity of $\mathrm{Al}_{4} \mathrm{H}_{6}$ is $1.25 \pm 0.15 \mathrm{eV}$, and the vertical detachment energy from the anionic cluster is $1.35 \pm 0.05 \mathrm{eV} .^{9}$ Our calculated affinity is $1.29 \mathrm{eV}$, very close to experiment.

The EAs shown in Fig. 3 have sizable values, between 0.58 and $2.06 \mathrm{eV}$. The lowest value $(0.58 \mathrm{eV})$ corresponds to $\mathrm{Al}_{6} \mathrm{H}_{8}$, a highly symmetrical cluster with the largest $\mathrm{H}-\mathrm{L}$ gap $(2.81 \mathrm{eV})$. There is, in fact, a high degree of correlation between the H-L gap of the neutral clusters and their EAs: Large gaps correspond to low values of the EAs. The only exception to this trend occurs for the affinity of $\mathrm{Al}_{10} \mathrm{H}_{12}$. Another interesting feature is noticeable: $\mathrm{Al}_{6} \mathrm{H}_{8}$ marks a transition between a trend of increasing gaps as the cluster size increases, at its left in the figure, and decreasing gaps on its

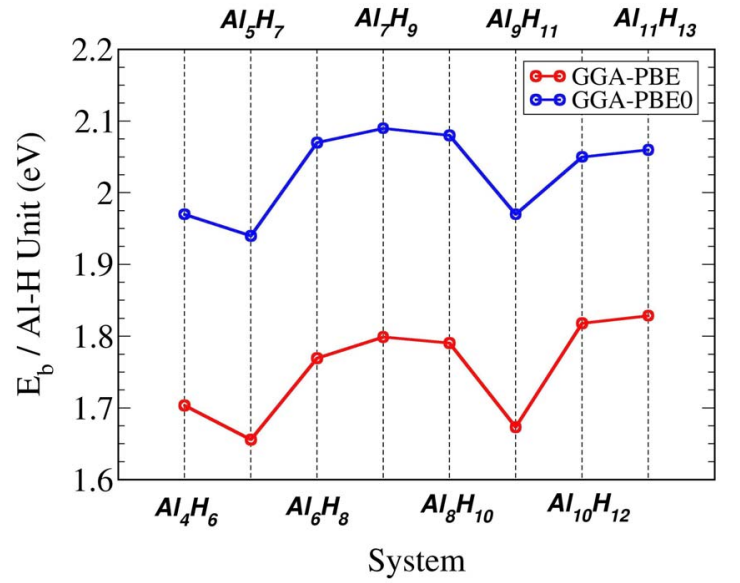

FIG. 4. (Color online) Cluster binding energies per AlH unit [see Eq. (1)] of $\mathrm{Al}_{n} \mathrm{H}_{n+2}$ clusters with $n=4-11$. Results obtained by using the PBE and PBE0 XC functionals are compared.

right. These features indicate that $\mathrm{Al}_{6} \mathrm{H}_{8}$ is the least reactive (or chemically most stable) cluster of this series. Recently, Kiran et al. ${ }^{17}$ calculated the $\mathrm{H}-\mathrm{L}$ gaps of $\mathrm{Al}_{6} \mathrm{H}_{2}, \mathrm{Al}_{7} \mathrm{H}, \mathrm{Al}_{7} \mathrm{H}_{3}$, $\mathrm{Al}_{8} \mathrm{H}_{4}, \mathrm{Al}_{13} \mathrm{H}$, and $\mathrm{Al}_{14} \mathrm{H}_{2}$, and the values range between 1.4 and $1.9 \mathrm{eV}$. The $\mathrm{Al}_{n} \mathrm{H}_{n+2}$ clusters studied here have larger gaps, between 1.35 and $2.8 \mathrm{eV}$, and will be chemically more stable.

Cluster binding energies per $\mathrm{AlH}$ unit have been calculated by subtracting the total energy of the $\mathrm{Al}_{n} \mathrm{H}_{n+2}$ cluster from the sum of the energies of $n \mathrm{AlH}$ molecules and one $\mathrm{H}_{2}$ molecule, and dividing the result by $n$

$$
E_{b} /(\mathrm{AlH} \text { unit })=\frac{E\left(\mathrm{H}_{2}\right)+n E(\mathrm{AlH})-E\left(\mathrm{Al}_{n} \mathrm{H}_{n+2}\right)}{n} .
$$

We have calculated this magnitude with the PBE and the hybrid PBE0 functionals. The results, shown in Fig. 4, reveal the same trend as the cluster size increases, with the PBE0 atomization energies displaying a constant shift of around $0.25 \mathrm{eV}$ to higher binding. The trend is a weak increase in the cluster binding energy with increasing cluster size, perturbed by a sharp fall for $\mathrm{Al}_{5} \mathrm{H}_{7}$ and $\mathrm{Al}_{9} \mathrm{H}_{11}$.

\section{B. Charge density analysis}

According to the WM rules for electron counting applied to these systems with $2 n+1$ pairs of valence electrons, $n$ of those pairs are required by the $\mathrm{Al}-\mathrm{H}$ terminal bonds, leaving $n+1$ pairs for cage bonding. We now analyze how the calculated densities fit into this picture. Figure 5 shows maps of the total electronic charge density $\rho_{\text {tot }}(\mathbf{r})$ of all the $\mathrm{Al}_{n} \mathrm{H}_{n+2}$ clusters. A pronounced concentration of charge can be appreciated in all the Al-H bonds corresponding to top $\mathrm{H}$ atoms. This charge is a little displaced toward the $\mathrm{H}$ atoms. For $\mathrm{Al}_{4} \mathrm{H}_{6}, \mathrm{Al}_{5} \mathrm{H}_{7}, \mathrm{Al}_{6} \mathrm{H}_{8}, \mathrm{Al}_{7} \mathrm{H}_{9}$, and $\mathrm{Al}_{10} \mathrm{H}_{12}$, this indicates that $n$ pairs of electrons are located just on the $n$ vertices of each cluster, in agreement with the WM rules. As indicated above, in $\mathrm{Al}_{n} \mathrm{H}_{n+2}$ with $n=8,9,11$, the number of $\mathrm{H}$ atoms on top positions is smaller than $n$. With respect to the other electrons, there is also a clear distinction between clusters with 

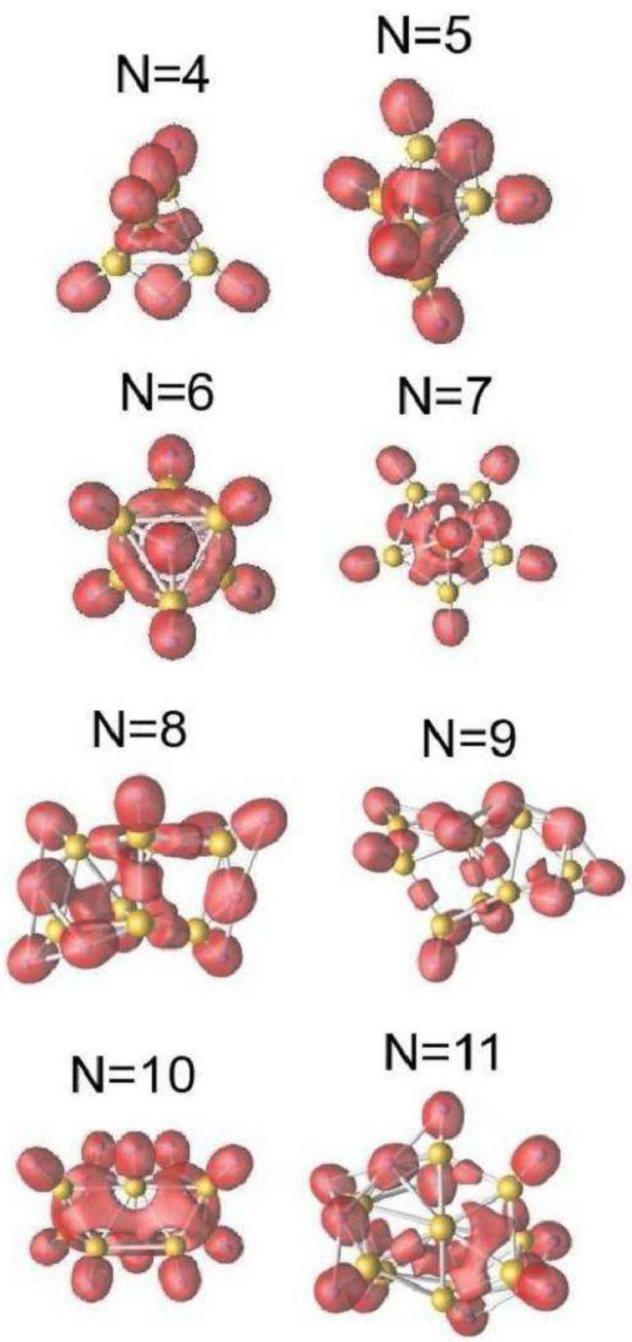

FIG. 5. (Color online) Surfaces of constant charge density $\left(0.05\right.$ e/a.u. $\left.{ }^{3}\right)$ for $\mathrm{Al}_{n} \mathrm{H}_{n+2}$ with $n=4-11$.

$n=4,5,6,7,10$ on one hand, and those with $n=8,9,11$ on the other. In the first group, the densities fit well into the WM picture of an electronic cloud delocalized over the surface of the $\mathrm{Al}$ cage. In contrast, for $\mathrm{Al}_{8} \mathrm{H}_{10}, \mathrm{Al}_{9} \mathrm{H}_{11}$, and $\mathrm{Al}_{11} \mathrm{H}_{13}$, the density is more localized, particularly in the regions between two $\mathrm{Al}$ atoms.

The spin-polarization densities of the cluster anions, $\mathrm{Al}_{n} \mathrm{H}_{n+2}^{-}$, obtained as the difference $\rho^{\uparrow}(\mathbf{r})-\rho^{\downarrow}(\mathbf{r})$ between the spin up and spin down densities, are plotted in Fig. 6. The spin-polarization densities are practically identical to the difference between the charge densities of the anion and the neutral $\rho\left[\mathrm{Al}_{n} \mathrm{H}_{n+2}^{-}\right](\mathbf{r})-\rho\left[\mathrm{Al}_{n} \mathrm{H}_{n+2}\right](\mathbf{r})$, not shown in the picture. To evaluate the last difference, the anionic and the neutral clusters are assumed to have the same geometrical structure as that of the ground state of the neutral. The neutrals are unpolarized systems, with an even number of electrons, and the extra electron occupies the LUMO of the neutral, leading to a magnetic moment of $1 \mu_{B}$ for the anionic clusters.

\section{Discussion of the WM rules}

In the previous subsections we have shown that the clusters $\mathrm{Al}_{4} \mathrm{H}_{6}, \mathrm{Al}_{5} \mathrm{H}_{7}, \mathrm{Al}_{6} \mathrm{H}_{8}, \mathrm{Al}_{7} \mathrm{H}_{9}$, and $\mathrm{Al}_{10} \mathrm{H}_{12}$ of the $\mathrm{Al}_{n} \mathrm{H}_{n+2}$
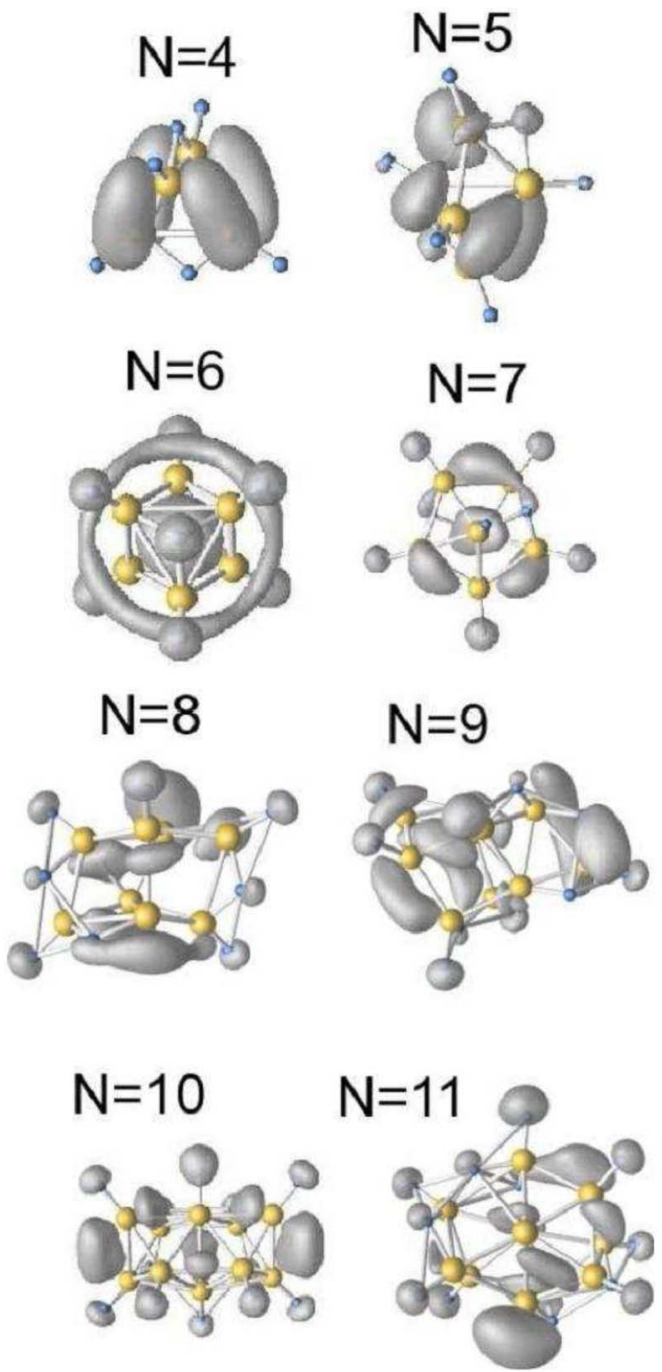

FIG. 6. (Color online) Surfaces of constant spin-polarization density $\left(0.001 e /\right.$ a.u. $\left.^{3}\right)$ for $\mathrm{Al}_{n} \mathrm{H}_{n+2}$ with $n=4-11$.

family fulfill the WM rule. That is, $n$ hydrogen atoms are bonded in top positions to the $\mathrm{Al}$ atoms of the matrix, which is a polyhedron with $n$ vertices. A pair of electrons is responsible for each of those strong $\mathrm{H}-\mathrm{Al}$ bonds, making a total of $n$ electron pairs. The other $n+1$ electron pairs form a cloud delocalized over the surface of the $\mathrm{Al}$ cage. In contrast, the clusters $\mathrm{Al}_{8} \mathrm{H}_{10}, \mathrm{Al}_{9} \mathrm{H}_{11}$, and $\mathrm{Al}_{11} \mathrm{H}_{13}$ do not fulfill those rules.

A key point in the fulfillment of the WM rule by the first group is the fact that the Al matrix of the hydrogenated cluster is a polyhedron with $n$ vertices. One then can ask to what extent this polyhedral structure is due to the presence of the adsorbed $\mathrm{H}$ atoms. As discussed above, the structure of the $\mathrm{Al}$ matrix in $\mathrm{Al}_{4} \mathrm{H}_{6}, \mathrm{Al}_{5} \mathrm{H}_{7}$, and $\mathrm{Al}_{6} \mathrm{H}_{8}$ is practically the same as in the corresponding pure $\mathrm{Al}$ clusters. On the other hand, the $\mathrm{Al}$ matrix in $\mathrm{Al}_{7} \mathrm{H}_{9}$ and $\mathrm{Al}_{10} \mathrm{H}_{12}$ is substantially distorted with respect to the pure $\mathrm{Al}_{7}$ and $\mathrm{Al}_{10}$ clusters. Actually, the distortion induced by the $\mathrm{H}$ atoms makes the $\mathrm{Al}$ cages in $\mathrm{Al}_{7} \mathrm{H}_{9}$ and $\mathrm{Al}_{10} \mathrm{H}_{12}$ more symmetrical, and this has a positive influence in the fulfillment of the $\mathrm{WM}$ rule. As for the question of why $\mathrm{Al}_{4} \mathrm{H}_{6}, \mathrm{Al}_{5} \mathrm{H}_{7}, \mathrm{Al}_{6} \mathrm{H}_{8}, \mathrm{Al}_{7} \mathrm{H}_{9}$, and $\mathrm{Al}_{10} \mathrm{H}_{12}$ fulfill the WM rule, but not the other three clusters, the only clear 
correlation we have found is that the former five clusters have a much more symmetrical structure than the other three. This point needs, evidently, further investigation.

\section{EXCITATION SPECTRUM}

We have calculated the photoabsorption spectrum of the $\mathrm{Al}_{n} \mathrm{H}_{n+2}$ clusters using the TDDFT. ${ }^{18,19,30}$ In particular, we have used the formalism developed by Casida ${ }^{31}$ and Jamorski et $a l .{ }^{32}$ implemented in the OCTOPUS code. ${ }^{29}$ In Casida's matrix formulation, the self-consistent solution of the ground-state KS equations is first obtained. Transitions between occupied and unoccupied single-particle KS states may then be regarded as a first approximation to the excitations. Then, in a second step, the KS frequencies and optical intensities are corrected to become the correct optical transitions of the many-body system. In this step we have employed the adiabatic local density approximation (LDA) XC kernel. Although this procedure is not entirely consistent because the ground-state KS single-particle orbitals and energy eigenvalues correspond to a GGA functional, only adiabatic LDA kernels are currently implemented in OCTOPUs and other common TDDFT codes. In addition, Koponen et al. ${ }^{33}$ concluded that the LDA performs much better in the TDDFT, compared to static DFT. On the other hand, the most important requirement in obtaining a good photoabsorption spectrum is to have accurate single-particle energies and orbitals, obtained with a good static XC potential, ${ }^{34,35}$ while the kernel is less important. The paper by Castro et al. ${ }^{19}$ presents a discussion of the influence of different XC kernels in the calculation of the optical spectrum of clusters by TDDFT.

Each excitation peak of the calculated spectrum has been broadened by a Lorentzian profile to give the photoabsorption cross section

$$
\sigma(\epsilon)=\sum_{\epsilon_{i}} \frac{A^{2}}{\left(\epsilon-\epsilon_{i}\right)^{2}+A^{2}} .
$$

In this equation $\epsilon$ represents the energy, the $\epsilon_{i}$ are the discrete excitation energies obtained by the Casida method, ${ }^{31,32}$ and the value of the parameter $A$ determines the full width at half maximum, set in this work equal to $0.05 \mathrm{eV}$, which is a value commonly used ${ }^{34}$ in order to simulate the available resolution in experiments of photoabsorption and photodissociative spectroscopy. This formalism has provided successful results in the calculation of the photoabsorption spectra of atoms, and different types of clusters, ${ }^{34-39}$ even at high excitation energies. ${ }^{35}$ Figure 7 shows the calculated photoabsorption cross sections of the neutral $\mathrm{Al}_{n} \mathrm{H}_{n+2}$ and anionic $\mathrm{Al}_{n} \mathrm{H}_{n+2}^{-}$clusters for excitation energies up to $12 \mathrm{eV}$. As discussed above, the cluster anions have the structure of the neutrals. Absorption begins at lower energies in the charged clusters, and these have more features at low energies than the neutral clusters. This occurs because the neutral clusters have an even number of electrons and large $\mathrm{H}-\mathrm{L}$ gaps (see Fig. 3), while the anionic clusters have odd number of electrons and the $\mathrm{H}-\mathrm{L}$ gaps are much smaller (between $0.08 \mathrm{eV}$ for $\mathrm{Al}_{9} \mathrm{H}_{11}^{-}$and $0.63 \mathrm{eV}$ for $\mathrm{Al}_{4} \mathrm{H}_{6}^{-}$). Returning to the neutrals,
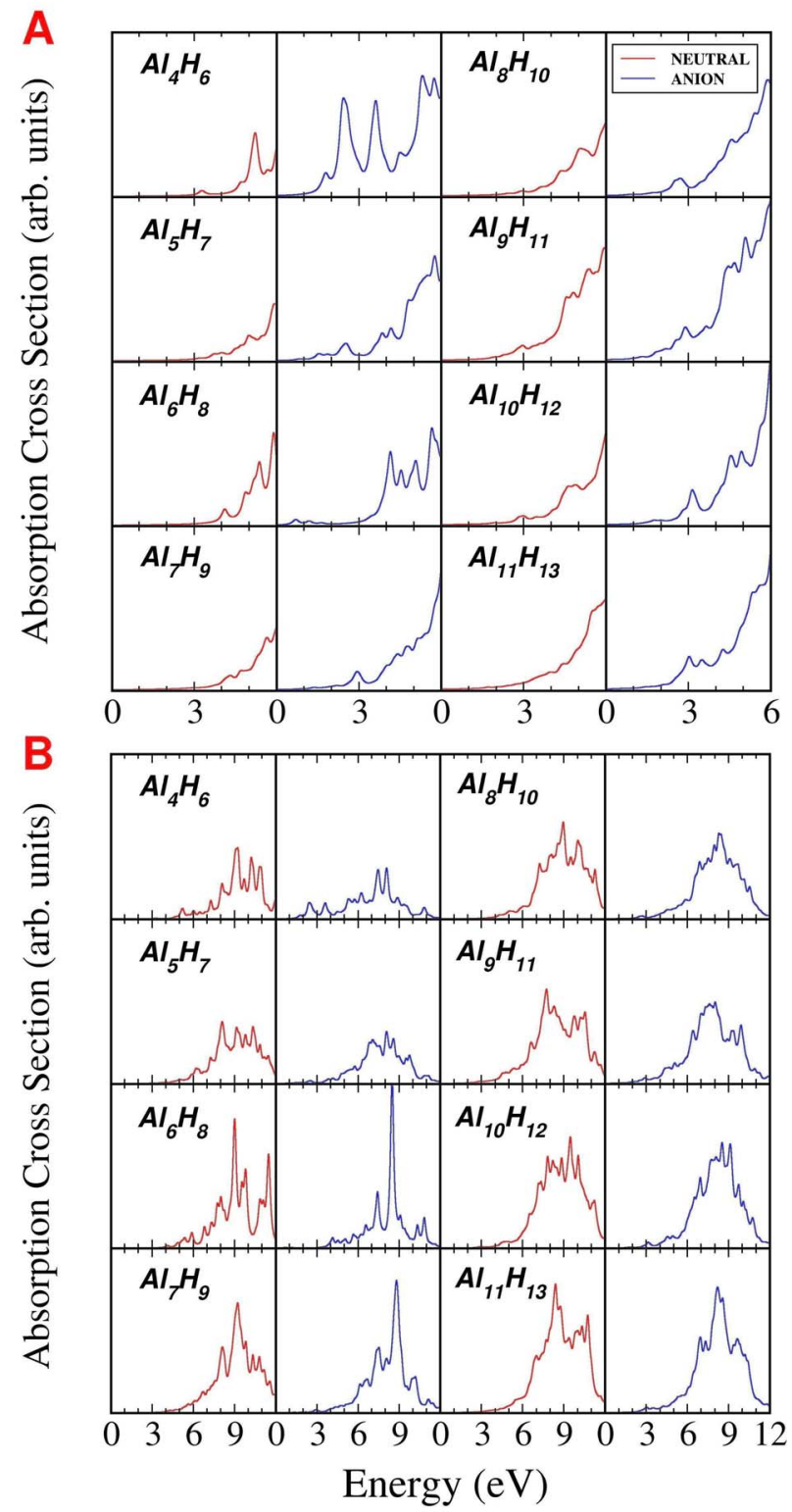

FIG. 7. (Color online) Calculated photoabsorption cross sections of neutral and anionic $\mathrm{Al}_{n} \mathrm{H}_{n+2}$ clusters with $n=4-11$ for excitation energies up to $6 \mathrm{eV}$ (panel A) and $12 \mathrm{eV}$ (panel B).

the absorption for the three clusters $\mathrm{Al}_{4} \mathrm{H}_{6}, \mathrm{Al}_{5} \mathrm{H}_{7}$, and $\mathrm{Al}_{6} \mathrm{H}_{8}$ begins at energies between 3 and $4 \mathrm{eV}$, and a trend can be appreciated of increasing absorption threshold from $\mathrm{Al}_{4} \mathrm{H}_{6}$ to $\mathrm{Al}_{5} \mathrm{H}_{7}$ and then to $\mathrm{Al}_{6} \mathrm{H}_{8}$. This is again correlated to the increasing H-L gap. For the rest the absorption threshold appears to decrease as a consequence of the decrease in the H-L gap. In the low energy region, the best defined absorption peaks occur for the most symmetrical clusters, $\mathrm{Al}_{4} \mathrm{H}_{6}$ and $\mathrm{Al}_{6} \mathrm{H}_{8}$. In the high excitation energy region all the spectra are very rich, and the spectra of the neutral and the corresponding charged species of the same size show clear similarities. All clusters have a wide absorption region between 6 and $11 \mathrm{eV}$. This absorption region suggests the possibility of delayed ionization and delayed emission of ions from the cluster following multiphoton absorption, as it has been observed $^{40}$ and explained for metal carbohedrenes. ${ }^{35}$ 


\section{SUMMARY AND CONCLUSIONS}

Motivated by the interest on the $\mathrm{Al}_{4} \mathrm{H}_{6}$ cluster, ${ }^{9}$ we have studied the family of hydrogenated $\mathrm{Al}$ clusters $\mathrm{Al}_{n} \mathrm{H}_{n+2}$ with $n=4-11$ using the DFT with the GGA approximation for XC. All these clusters have $2 n+1$ valence electron pairs. The main characteristic is that the clusters have sizable H-L gaps and, consequently, they are chemically very stable. The largest gap of $2.81 \mathrm{eV}$ occurs for $\mathrm{Al}_{6} \mathrm{H}_{8}$. Five clusters of the family, $\mathrm{Al}_{4} \mathrm{H}_{6}, \mathrm{Al}_{5} \mathrm{H}_{7}, \mathrm{Al}_{6} \mathrm{H}_{8}, \mathrm{Al}_{7} \mathrm{H}_{9}$, and $\mathrm{Al}_{10} \mathrm{H}_{12}$, fulfill the WM rule, as earlier discovered for $\mathrm{Al}_{4} \mathrm{H}_{6}$ by Li et al. ${ }^{9}$ That is, in the $\mathrm{Al}_{n} \mathrm{H}_{n+2}$, the $\mathrm{Al}$ matrix forms a polyhedron of $n$ vertices and $n$ hydrogen atoms of the cluster form strong $\mathrm{H}-\mathrm{Al}$ terminal bonds. One pair of electrons is involved in the formation of each of those bonds. The remaining $n+1$ electron pairs form a cloud delocalized over the surface of the $\mathrm{Al}$ cage. The other three clusters, $\mathrm{Al}_{8} \mathrm{H}_{10}, \mathrm{Al}_{9} \mathrm{H}_{11}$, and $\mathrm{Al}_{11} \mathrm{H}_{13}$ do not conform to this rule. The clusters fulfilling the WM rule have wider $\mathrm{H}-\mathrm{L}$ gaps and are then chemically more stable (although the gap of $\mathrm{Al}_{10} \mathrm{H}_{12}$ is smaller than the gap of $\mathrm{Al}_{8} \mathrm{H}_{10}$, it is a local maximum with respect to neighbor clusters). The trends in the H-L gap have some reflection in the behavior of the photoabsorption spectrum. This has been calculated by the Casida method in the frame of TDDFT, using PBE single-particle energies and orbitals and an LDA XC kernel.

\section{ACKNOWLEDGMENTS}

This work was supported by MEC of Spain (Grant No.MAT2005-06544-C03-01) and by Junta de Castilla y León (Grant No. VA039A05). The Center for Atomic-scale Materials Design is funded by the Lundbeck Foundation. J.I.M. wishes to acknowledge additional support from the Danish Research Agency through Grant No. 26-04-0047 and the Danish Center for Scientific Computing through Grant No. HDW-0107-07. He also wishes to acknowledge discussions with D. J. Mowbray. J.A.A. acknowledges the hospitality and support of the Donostia International Physics Center.

${ }^{1}$ W. D. Knight, K. Clemenger, W. A. de Heer, W. A. Saunders, M. Y. Chou, and M. L. Cohen, Phys. Rev. Lett. 52, 2141 (1984).

${ }^{2}$ J. A. Alonso, Structure and Properties of Atomic Clusters (Imperial College Press, London, 2005).

${ }^{3}$ L. Andrews and X. Wang, Science 299, 2049 (2003).

${ }^{4}$ F. A. Kurth, R. A. Eberlein, H. Schnöckel, A. J. Downs, and C. R. Pulham, J. Chem. Soc., Chem. Commun. 16, 1302 (1993).

${ }^{5}$ P. Breisacher and B. Siegal, J. Am. Chem. Soc. 86, 5053 (1964).

${ }^{6}$ F. A. Cotton and G. Wilkinson, Advanced Inorganic Chemistry (Interscience, New York, 1966).

${ }^{7}$ S. Burkart, N. Blessing, B. Klipp, J. Müller, G. Gateför, and G. Seifert, Chem. Phys. Lett. 301, 546 (1999).
${ }^{8}$ B. K. Rao, P. Jena, S. Burkart, G. Gamteför, and G. Seifert, Phys. Rev. Lett. 86, 692 (2001).

${ }^{9}$ X. Li, A. Grubisic, S. T. Stokes, J. Cordes, G. F. Ganteför, K. H. Bowen, B. Kiran, M. Willis, P. Jena, R. Burgert, and H. Schnöckel, Science 315, 356 (2007).

${ }^{10}$ K. J. Wade, Adv. Inorg. Chem. Radiochem. 18, 1 (1976).

${ }^{11}$ K. J. Wade, J. Chem. Soc., Chem. Commun. 15, 792 (1971).

${ }^{12}$ D. M. P. Mingos, Nature (London), Phys. Sci. 236, 99 (1972).

${ }^{13}$ J. W. Lauher, J. Am. Chem. Soc. 100, 5305 (1978).

${ }^{14}$ E. D. Jemmis, M. M. Balakrishnarajan, and P. D. Pancharatna, J. Am. Chem. Soc. 123, 4313 (2001).

${ }^{15}$ M. M. Balakrishnarajan and R. Hoffman, J. Am. Chem. Soc. 126, 13119 (2004).

${ }^{16}$ M. A. Cavanaugh, T. P. Fehlner, R. Stramel, M. E. O’Neill, and K. J. Wade, Polyhedron 4, 687 (1985).

${ }^{17}$ B. Kiran, P. Jena, X. Li, A. Grubisic, S. T. Stokes, G. F. Ganteför, K. H. Bowen, R. Burgert, and H. Schnöckel, Phys. Rev. Lett. 98, 256802 (2007).

${ }^{18}$ M. A. L. Marques and E. K. U. Gross, Annu. Rev. Phys. Chem. 55, 427 (2004).

${ }^{19}$ A. Castro, M. A. L. Marques, J. A. Alonso, and A. Rubio, J. Comput. Theor. Nanosci. 1, 231 (2004).

${ }^{20}$ X. Gonze, J. M. Beuken, R. Caracas, F. Detraux, M. Fuchs, G. M. Rignanese, L. Sindic, M. Verstraete, G. Zerah, F. Jollet, M. Torrent, A. Roy, M. Mikami, Ph. Ghosez, J. Y. Raty, and D. C. Allan, Comput. Mater. Sci. 25, 478-492 (2002); see http://www.abinit.org.

${ }^{21}$ N. Troullier and J. L. Martins, Phys. Rev. B 43, 1993 (1991).

${ }^{22}$ M. Fuchs and M. Scheffler, Comput. Phys. Commun. 119, 67 (1999).

${ }^{23}$ J. P. Perdew, K. Burke, and M. Ernzerhof, Phys. Rev. Lett. 77, 3895 (1996); 78, 1396 (1997).

${ }^{24}$ R. van Leeuwen and E. J. Baerends, Phys. Rev. A 49, 2421 (1994)

${ }^{25}$ M. Ernzerhof and G. E. Scuseria, J. Chem. Phys. 110, 5029 (1999); C. Adamo, G. E. Scuseria, and V. Barone, J. Chem. Phys. 111, 2889 (1999).

${ }^{26}$ B. K. Rao and P. Jena, J. Chem. Phys. 111, 1890 (1999).

${ }^{27}$ A. Mañanes, F. Duque, F. Méndez, M. J. López, and J. A. Alonso, J. Chem. Phys. 119, 5128 (2003).

${ }^{28}$ B. K. Rao, P. Jena, S. Burkart, G. Ganteför, and G. Seifert, Phys. Rev. Lett. 86, 692 (2001).

${ }^{29}$ M. A. L. Marques, A. Castro, G. F. Bertsch, and A. Rubio, Comput. Phys. Commun. 151, 60 (2003).

${ }^{30}$ M. Petersilka, U. J. Gossmann, and E. K. U. Gross, Phys. Rev. Lett. 76, 1212 (1996).

${ }^{31}$ M. E. Casida, in Recent Advances in Density Functional Methods, edited by D. P. Chong (World Scientific, Singapore, 1995), Pt. 1, p. 155.

${ }^{32}$ C. Jamorski, M. E. Casida, and D. R. Salahub, J. Chem. Phys. 104, 5134 (1996).

${ }^{33}$ L. Koponen, L. Tunturivouri, M. J. Puska, and R. M. Nieminen, J. Chem. Phys. 126, 214306 (2007).

${ }^{34}$ J. I. Martínez, A. Castro, A. Rubio, and J. A. Alonso, J. Comput. Theor. Nanosci. 3, 761 (2006).

${ }^{35}$ J. I. Martínez, A. Castro, A. Rubio, and J. A. Alonso, J. Chem. Phys. 125, 074311 (2006).

${ }^{36}$ J. I. Martínez and J. A. Alonso, Phys. Rev. B 76, 205409 (2007).

${ }^{37}$ J. I. Martínez, M. Isla, and J. A. Alonso, Eur. Phys. J. D 43, 61 (2007).

${ }^{38}$ I. Vasiliev, S. Ogut, and J. R. Chelikowsky, Phys. Rev. Lett. 82, 1919 (1999).

${ }^{39}$ D. Tsolakidis, D. Sánchez-Portal, and R. M. Martin, Phys. Rev. B 66, 235416 (2002).

${ }^{40}$ B. D. May, S. F. Cartier, and A. W. Castleman, Chem. Phys. Lett. 242, 265 (1995). 